\title{
POLÍTICAS DE AVALIAÇÃO E SUBJETIVAÇÃO DOCENTE: UMA ANÁLISE CURRICULAR PÓS-FUNDACIONAL
}

\author{
Carmen Teresa Gabriel \\ Marcus Leonardo Bomfim Martins ${ }^{(*)}$
}

Se o conceito de posição do sujeito explica as múltiplas formas pelas quais indivíduos são produzidos como atores sociais, o conceito de subjetividade política capta a maneira como atores sociais agem. (HOWARTH, 2000, p.108)

O presente texto tem por objetivo analisar processos de subjetivação docente em meio às políticas de avaliação em nossa contemporaneidade, a partir das contribuições teóricas dos estudos curriculares mais recentes, em particular aqueles oriundos do estreitamento do diálogo deste campo com as teorizações do discurso na pauta pós-fundacional. Sem dúvida, a incorporação teórica das abordagens discursivas pós-fundacionais no campo do currículo têm aberto outras possibilidades de leituras sobre temas clássicos como os que mobilizam, por exemplo, as interfaces currículoavaliação e/ou currículo-docência que constituem o foco de reflexão deste texto como indica seu título.

Questões que envolvem essas duas interfaces atravessam os debates curriculares assumindo contornos e ênfases diferenciadas em função dos recortes e perspectivas teóricas privilegiadas nas análises das quais são objeto. Neste texto, assumindo a virada ontológica que configura a postura epistêmica pós-fundacional, propomos um recorte como porta de entrada nesses debates pelo qual as políticas de avaliação são tomadas como contexto discursivo ou campos de tensionamento. Interessa-nos, particularmente explorar os processos de subjetivação docente em relação aos processos de produção e circulação do conhecimento escolar fixado hegemonicamente nessas políticas.

Trata-se pois, de um exercício teórico que se inscreve em um movimento mais amplo de reafirmação do potencial heurístico da virada ontológica na produção de leituras políticas do social, em particular do campo curricular. O que está em jogo é a possibilidade de continuarmos operando em nossas pesquisas com categorias como 'sujeito', posicionado como docente, e 'conhecimento', adjetivado de escolar, após a radicalização das críticas às perspectivas essencialistas e deterministas

\footnotetext{
${ }^{(*)}$ Carmen Teresa Gabriel. Professora Titular de Currículo da Faculdade de Educação (FE/UFRJ) e professora do Programa de Pós-Graduação em Educação (PPGE/UFRJ).

Marcus Leonardo B. Martins. Doutorando em Educação (PPGE/UFRJ); Professor de História (C. E. Golda Meir); Técnico em Assuntos Educacionais (EQ/UFRJ)
} 
de mundo. Pensar 'educação', 'currículo', 'escola', 'conhecimento', 'professor/a', 'aluno/a' sem cair em um subjetivismo metafisico, tampouco em um objetivismo positivista essencialista. Pensar essas palavras e quaisquer outras palavras -, sabendo que o desafio é justamente ficarmos no nível das palavras, reconhecendo, ao mesmo tempo, que ao fazê-lo não se está só com as palavras. Afinal, a crítica à ideia de essência, tal como formulada na pauta pós-fundacional, exige assumirmos as implicações políticas, epistemológicas e ontológicas de nossa condição de ser na e da linguagem e que é dessa e nessa condição que pensamos, significamos e agimos no mundo.

A escolha por esse arranjo discursivo entre os significantes políticas de avaliação, currículo e docência, não foi aleatória. Ela diz de nossos interesses de pesquisa no campo do currículo e de nossas apostas políticas em termos de investimento nas lutas pela hegemonização de um projeto particular de escola pública para todos/as em nossa contemporaneidade que passa, em nossa interpretação, necessariamente pela valorização da cultura profissional docente. Participar das lutas pela significação por termos como 'docência' e 'conhecimento', é, entendemos, um caminho possível de participação nessas disputas.

O protagonismo que as políticas de avaliação vêm assumindo nas políticas educacionais brasileiras desde a última década do século passado, e em particular o seu efeito sobre o entendimento de sentidos de docência e de conhecimento nos parece justificar a sua escolha como contexto discursivo para a análise aqui proposta. Como apontam diferentes estudos (SOUSA; OLIVEIRA, 2010; SILVA et al, 2013), as políticas de avaliação não ficaram restritas à gestão nacional da educação brasileira em seus diversos níveis, mas difundiram-se também nos sistemas estaduais e até mesmo municipais de ensino, independente da orientação político-partidária vigente nestas escalas de organização político-administrativa do Estado, o que levou Afonso (2007) a alcunhar essa proliferação de políticas educacionais como uma verdadeira "obsessão avaliativa".

A presença ostensiva de políticas de avaliação para a educação básica no Brasil está assente na opção do país em fazer parte do Programa Internacional de Avaliação de Estudantes (Pisa). Essa opção justifica o interesse nesse tipo de política, gerando, muitas vezes, profusão e sobreposição de avaliações nas escolas, retirando, inclusive, tempo para o desenvolvimento de práticas curriculares voltadas ao ensino e à aprendizagem.

Por profusão de avaliações, entendemos o acúmulo de diferentes tipos e lógicas de avaliação, como por exemplo, a prova elaborada pelo próprio professor, as avaliações da secretaria à qual a escola esteja submetida e a avaliação de âmbito nacional, sem contar eventuais simulados e testes. Esse congestionamento de instrumentos avaliativos pode gerar, inclusive, reações, por parte 
dos sujeitos por elas afetados, opostas às desejadas por quem pensou aquela avaliação, como descaso, repulsa e negligência.

Em relação à sobreposição de avaliações, referimo-nos as avaliações que possuam o mesmo desenho, implicando na obtenção dos mesmos resultados. O desenho de cada avaliação condiciona as possibilidades de realização de diagnósticos, ou seja, dependendo da forma como a avaliação é pensada, produzida e aplicada, ela pode produzir resultados apenas sobre uma rede, ou sobre a escola ou sobre uma turma, ou individualmente sobre cada aluno.

Essas políticas têm pois, sido objeto de intensos debates entre aqueles que, dentre outros aspectos, enfatizam os seus efeitos danosos sobre as práticas curriculares e relações sociais circunscritas ao espaço escolar, e grupos que defendem essas políticas como caminho para a reestruturação da gestão dos sistemas de ensino com base em aspectos consolidados do mundo empresarial: eficiência, eficácia e qualidade, tendo sempre como objetivo assegurar a "qualidade da educação", entendida de forma redutora como sendo o desempenho positivo de alunos/as mensurado pelos instrumentos de avaliação. Esse modelo gerencialista tem se firmado no Brasil desde a década de 1990, acompanhando "uma agenda e tendências internacionais já consolidadas que enxergam nesse tipo de ação uma forma de se aferir a qualidade e a efetividade dos sistemas educacionais." (SILVA, 2013, p. 1), participando assim, do processo de redefinição do papel do Estado perante as políticas públicas educacionais.

De acordo com Hypolito e Ivo (2013) esse modelo articula currículo, gestão e trabalho docente em uma perspectiva de racionalidade instrumental em busca de eficiência. $\mathrm{O}$ modelo gerencialista, ao privilegiar apenas os resultados obtidos pelos alunos em avaliações externas, teria como objetivo, de acordo com esses autores, responsabilizar os professores pelo fracasso escolar, eximindo os gestores (no caso, o poder público) de suas responsabilidades. Não fica assim difícil de reconhecer os efeitos produzidos por essas políticas sobre os sujeitos posicionados no espaço escolar, bem como sobre os conhecimentos que aí circulam.

Desse modo, entendemos que as políticas de avaliação podem ser vistas como terreno favorável para pensar os processos de subjetivação docente tanto em termos de assujeitamento como de produção de subjetividades políticas. Dito de outra forma, no enfoque privilegiado neste texto, essas políticas são percebidas como campos de tensionamento entre sujeitos/docentes e estruturas, isto é, entre processos de subjetivação e processos de estruturação da docência como campo de atuação profissional. A pergunta que tem orientado nossas reflexões pode ser assim formulada: Em tempos de "obsessão avaliativa" como pensar os processos de subjetivação docente de forma a não reafirmar posições binárias que ora insistem em significar a docência como lócus de 
socialização profissional, reprodutor de discursos hegemônicos sobre esse ofício, ora contribuem para fixar o sentido de docência como lugar de subjetivação e identificação abrindo espaço para se pensar outras possibilidades de vivenciar e significar essa cultura profissional?

A saída teórica que vimos ensaiando em nossas pesquisas (AUTOR 1; AUTOR 2) para enfrentar esse tipo de questionamento consiste em reafirmar o papel chave desempenhado pela articulação com o conhecimento disciplinarizado para a reflexão aqui proposta. Trata-se de reconhecer que a compreensão da docência como campo de estruturação de uma ordem desigual pressupõe inscrevê-la em um sistema hierarquizado de saberes historicamente construídos.

Organizamos nossos argumentos para sustentar essa hipótese em três seções. Na primeira apresentamos o quadro de inteligibilidade pós-fundacional no qual as nossas reflexões e análises se inscrevem. A segunda seção focaliza o debate teórico em torno da tensão entre processos de estruturação (campo da docência) e processos de subjetivação docente face às políticas de avaliação hegemonizadas no cenário educacional contemporâneo, evidenciando o potencial heurístico de categorias como 'sujeito', 'antagonismo' e 'demanda' formuladas no âmbito do quadro teórico aqui privilegiado. Por último, apresentamos algumas apostas políticas que implicam na construção de demandas de conhecimento consideradas potentes para deslocar do lugar da subalternidade o sujeito-docente em meio ao sistema de saberes hierarquizados que participam da estruturação do campo da docência.

\section{NOMEAR É UM ATO POLÍTICO}

[...] o conceito de discurso na teoria de Laclau e Mouffe captura a ideia de que todos os objetos e ações são significativos, e que seus significados são conferidos por sistemas particulares de diferenças significativas [... e que ...] o sentido de 'ser' [das coisas] depende dos sistemas particulares de diferença ou discursos que constituem sua identidade. [...] (HOWARTH, 2005 p.101-102, tradução nossa)

Na perspectiva pós-fundacional com a qual temos dialogado (LACLAU; MOUFFE, 2004; MARCHART, 2010, RETAMOZO, 2009), definir, significar, conceituar, nomear são atos políticos na medida em que a radicalização da crítica às leituras essencialistas e deterministas, decorrente do enfraquecimento ontológico do fundamento, permite afirmar que qualquer definição significa um fechamento contingente e provisório resultante de uma operação hegemônica em meio ao jogo politico no qual ela está sendo acionada. A abordagem discursiva pós-fundacional aposta em uma leitura de mundo que reafirma outro quadro de inteligibilidade no qual é possível superar uma leitura dicotômica que coloca em polos opostos "o mundo dos objetos" e o "mundo etéreo dos signos". Nas palavras de Laclau (2005): 
Por discurso não entendemos algo essencialmente restrito às áreas da fala e da escrita, como temos declarado várias vezes, mas sim um conjunto de elementos no qual as relações exercem uma força constitutiva. Isto significa que estes elementos não são preexistentes ao complexo relacional, mas que se constituem por meio dele. Portanto, "relação" e "objetividade" são sinônimas. (LACLAU, 2005, p. 92, tradução nossa, grifo do autor).

Importa sublinhar contudo, que o pós-fundacionalismo se diferencia de uma postura epistêmica anti-fundacional. Nesta última, nega-se a possibilidade de qualquer fundamento, na primeira, o que é negado é sua transcendentalidade, percebendo-o, portanto, como contingente e histórico. Desse modo, o reconhecimento da ausência de um fundamento último sobre o qual se apoiariam as definições, isto é, de fechamentos que possibilitam fixar e estabilizar processos de significações não apaga a necessidade ou inevitabilidade de uma proposta de fundamento, mas, altera seu status ontológico (MARCHART, 2009). A abordagem pós-fundacional radicaliza as críticas às leituras essencialistas de mundo, desconfiando das afirmações categóricas e das generalizações, dando preferência às interpretações parciais e localizadas, pois, como afirma Marchart (2009), esse quadro de inteligibilidade permite uma "[...] dissolução dos marcadores de certeza específicos como fundamento do social [...]” (MARCHART, 2009, p. 19).

São essas múltiplas possibilidades de nomear/interpretar o mundo que mantém a provisoriedade do fundamento. Ao invés de serem percebidos como estanques, definitivos, únicos, completos e transcendentes, eles passam a ser significados como fechamentos precários, provisórios, parciais, contingentes, exercendo uma função discursiva indispensável em meio ao jogo da linguagem para que a significação aconteça. Esse jogo de linguagem obedece, por sua vez, a duas lógicas - da equivalência e da diferença - inerentes aos processos de produção e fixação de sentidos provisórios. A primeira é responsável pela produção de cadeias de equivalência, por meio do enfraquecimento das diferenças entre seus elementos, sem no entanto eliminá-las por completo. A lógica de equivalência para cumprir sua função discursiva pressupõe, no entanto, a mobilização e radicalização da lógica da diferença que é responsável pelo estancamento dessas cadeias, por meio da produção de diferenças radicais, de limites, que funcionam como um "bloqueio da expansão contínua do processo de significação" (LACLAU; MOUFFE, 2004). Com efeito, o mesmo movimento que faz com que um significante se torne capaz de suturar, ainda que provisoriamente, uma cadeia de equivalências entre unidades diferenciais e definir algo, expele para fora desta meia cadeia discursiva o outro, o antagônico, isto é outras unidades diferenciais que passam a constituir seu exterior constitutivo. 
O desafio teórico-metodológico consiste pois, em compreender e operar com essas duas lógicas anteriormente mencionadas. Como Laclau (2005) nos provoca a pensar, o discurso é justamente o resultado desses processos se apresentando como uma totalidade discursiva estruturada por meio de relações estabelecidas entre unidades diferenciais (significantes, termos, palavras, expressões) que fora desta relação não carregam nenhum sentido prefixado. Não é por acaso que o significante articulação torna-se uma das principais noções trabalhadas nesse quadro teórico. São as práticas articulatórias - responsáveis pela mobilização dessas duas lógicas - que constituem e organizam as relações sociais. Nessa abordagem, as noções de "dispersão" e "heterogeneidade" podem ser vistas em toda a sua complexidade quando pensadas de forma articulada às possibilidades de fechamentos ou suturas. E essa possibilidade nos parece profícua na medida em que sem fechamentos contingenciais não há jogo político possível.

Nesse movimento, definir, significar, fechar, suturar são operações que tendem a hegemonizar / universalizar um sentido particular em meio às lutas pela significação. A cadeia equivalencial, quando tem êxito e se torna hegemônica, favorece as sedimentações ou estabilizações de sentidos. Porém, se os sedimentos se reativam, há uma "temporalização do espaço" ou uma “extensão do campo do possível”, dando-se um momento de reativação, com um processo de desfixação de sentidos (MARCHART, 2009, p. 185). Nesse mesmo movimento de hegemonização/homogeneização que investe na necessidade de fechamento e de sutura, é que emerge o antagonismo, reafirmando a impossibilidade de qualquer fechamento definitivo. Afinal, os antagonismos revelam

(...) os limites ou fronteiras políticas de uma formação social, porque eles mostram os pontos onde a identidade não pode mais ser estabilizada em um sistema de diferenças significativo, sendo contestada por forças que se situam no limite daquela ordem. (HOWARTH, 2000, p. 5)

Destarte, operar na pauta pós-fundacional implica em abrirmos mão de certezas e verdades entendidas como algo que se situaria fora do jogo da linguagem (GABRIEL, 2013). Argumentamos que é justamente no jogo da linguagem que são definidas o que em cada espaço-tempo é considerado e validado como verdade ou se preferirmos, que são fixados contingencialmente regimes de verdade.

Nessa postura epistêmica o significante 'Social' se diferencia de significantes como 'realidade social', 'ordem social' ou 'sociedade'. O primeiro nomeia um "espaço indeterminado e potencialmente infinito de práticas humanas sedimentadas” (RETAMOZO, 2009, p. 112), os demais são termos mobilizados para significar formas particulares de fechamentos resultantes de 
operações hegemônicas produzidas em um campo infinito de possibilidades de estabilizações e sedimentações de sentido. A realidade social não está dada a priori, tampouco aparece como algo a ser desvendado, pois não há algo cujo sentido esteja fora da discursividade. Ou seja, ao produzir enunciados sobre o que nos propomos a aqui analisar, estamos construindo esta realidade social, que só existe como tal a partir do momento que a instituímos por meio de práticas articulatórias significativas. São, pois, as relações que desempenham um papel constitutivo, que objetivam todo e qualquer discurso. Como temos argumentado, a objetivação ou fechamento provisório e contingencial de uma cadeia de definição é o que torna o jogo político possível. Nesse quadro de inteligibilidade não é por acaso que o político é percebido como o "ontológico do social”. O social é, pois, produzido discursivamente em meio a lutas políticas por hegemonização de significados particulares. Seguindo essa linha argumentativa, a política seria o "campo empírico" para se pensar o político. A distinção conceitual entre político e política pode ser assim explicitada:

Alguns teóricos como Hannah Arendt veem o político como um espaço de liberdade e de deliberação pública, enquanto outros o veem como espaço de poder, conflito e antagonismo. Meu entendimento do 'político' claramente pertence à segunda perspectiva. Mais precisamente, esta é a forma como eu distingo o 'político' da 'política': por 'o político' eu entendo a dimensão do antagonismo a qual eu tomo como constitutiva das sociedades humanas, enquanto que por 'política' eu significo uma série de práticas e instituições através das quais uma ordem é criada, organizando a coexistência humana no contexto de conflitualidade provida pelo político. (MOUFFE, 2005 apud MENDONÇA, 2010, p. 485).

Não existe, portanto, a partir dessa perspectiva, um centro de poder, seja uma estrutura ou um sujeito, que já fosse determinado em si mesmo, que fosse portador de uma essência, e, no caso do problema levantado para este texto, que definiria aprioristicamente o significado de docência. Nesse sentido o que confere contornos de estrutura a uma determinada totalidade discursiva não é a presença de um centro metafisicamente definido, mas sim seu elevado grau de reprodutibilidade, ou em outros termos, a estabilidade da sua hegemonização para além de seu caráter contingente. Assumir que as estruturas são descentradas significa dizer que elas conferem brechas para as ações dos sujeitos que, longe de estarem condenados a repetibilidade, e/ou igualmente distantes da plena autonomia, tomam decisões, independentemente da posição ocupada em qualquer ordem social particular.

Diante do exposto, as políticas de avaliação são aqui entendidas como campo empírico onde ocorrem as lutas pela hegemonização de processos de estruturação/ estabilização do campo 
profissional da docência em meio aos diferentes interesses que participam e disputam o jogo da definição desse ofício.

\section{POLÍTICAS DE AVALIAÇÃO COMO CAMPO DE ESTABILIZAÇÃO DO POLÍTICO}

Conforme abordado na introdução, as políticas de avaliação assumem na contemporaneidade um papel de protagonista nas políticas educacionais. Estudos recentes (MARTINS, 2018) têm aberto pistas investigativas que permitem considerá-las como espaços de hegemonização de sentidos do que deve ser ensinado/aprendido nas escolas da educação básica interpelando assim, diretamente os sujeitos posicionados nas relações de ensino-aprendizagem como professores e alunos. Nos limitamos, neste texto, a evidenciar os efeitos dessas políticas nos processos de subjetivação docente

É comum por parte de professores da educação básica e de pesquisadores do campo educacional críticos das políticas de avaliação, a utilização dos argumentos de que as avaliações oficiais retiram a autonomia docente, ignoram as diferenças culturais dos sujeitos circulantes nas escolas, instauram um ambiente de competição dentro das escolas e entre escolas, principalmente quando são atreladas a políticas de responsabilização, entendidas por Brooke (2008) como sendo uma:

(...) tentativa de melhorar os resultados das escolas mediante a criação de consequências para a escola ou para professores individuais, sejam elas materiais ou simbólicas, de acordo com o desempenho dos alunos medidos por procedimentos avaliativos estaduais ou municipais. (BROOKE, 2008, p. 94).

Este tema é bastante sensível e polêmico, dados os pressupostos que esse tipo de política apresenta. Indubitavelmente, trata-se de um elemento com grande potencial de participação na produção de subjetividades docentes. Estados Unidos e Inglaterra foram os países pioneiros nesse tipo de política para induzir melhorias nos resultados escolares. "Nesses países, o argumento era que as instâncias governamentais locais e as escolas precisavam assegurar que a autonomia dos professores estivesse a serviço da aprendizagem dos alunos mediante a aferição e a cobrança de resultados." (BROOKE, 2006, p. 385).

Esse argumento traz de forma implícita a mensagem de que a autonomia docente não tem produzido bons resultados escolares, necessitando assim, ser redefinida. Esta, porém, é apenas uma faceta das tensões que envolvem esse tipo de política que tem na culpabilização dos atores escolares pelos resultados dos alunos nas avaliações externas de larga escala a sua principal característica. 
Percebe-se nos discursos produzidos para legitimar as avaliações oficiais de larga escala, a recorrência à questão da qualidade da própria atuação docente para justificar o investimento nessa política. Os discursos que tendem a ser estabilizados nessas políticas de avaliação investem nas políticas de responsabilização como efeito indutor da melhoria dos resultados educacionais. Pontual (2008) argumenta que a sofisticação técnica presente nas avaliações oficiais e na produção de dados estatísticos referentes a elas permitem - nos próprios termos desta autora-, com objetividade e precisão, identificar escolas que não atingiram desempenho que seja considerado satisfatório. Nessa perspectiva, a remuneração variável dos professores, passou a ser uma opção disponível. De acordo com Pontual (2008):

espera-se alinhar os interesses do aluno aos dos professores e assim motivar o professor a aumentar seu esforço dentro da sala de aula, contribuir para a profissionalização do magistério, estimular professores a investirem no seu próprio desenvolvimento profissional, assim como atrair professores mais bem qualificados para a profissão. (PONTUAL, 2008, p. 5).

Esse tipo de argumentação, presente na citação acima, não apenas sustenta uma percepção da docência como uma cultura profissional desqualificada, como contribui para reafirmar a posição de subalternidade do docente nessas políticas. Interessa-nos argumentar contra esse tipo de visão a partir da mobilização de algumas ferramentas teóricas formuladas nas teorizações do discurso na pauta pós-fundacional em particular as categorias 'sujeito', 'demanda' e 'antagonismo'.

Trata-se de, no contexto discursivo aqui privilegiado - as políticas de avaliação - buscar uma maior abertura para pensar outros sentidos de docência vista como campos de estruturação nos quais os sujeitos docentes "no lugar de condenados à repetição, podem abrir a diferença, constituirse e expandir os efeitos deslocatórios" (RETAMOZO, 2009, p. 115). Olhar para a docência não mais como algo essencializado, isto é, visto como identidade plenamente positivada, mesmo quando, como é o caso muitas vezes, sua historicidade é reconhecida ${ }^{1}$ mas sim, como um campo de estruturação de uma cultura profissional resultante de camadas de sedimentação de fluxos de sentidos deste significante hegemonizados contingencialmente e que por meio de diferentes dispositivos conseguem permanecer hegemônicos.

\footnotetext{
${ }^{1} \mathrm{Na}$ abordagem aqui privilegiada não basta reconhecer a historicidade de qualquer significante para operar na pauta anti-essencialista. Os termos história, historicidade se encontram igualmente em meio às disputas pelo preenchimento de seu sentido nos diversos contextos discursivos em que são mobilizados. Como problematizado em outra ocasião (AUTOR1, ANO): O que entender por historicidade quando algumas garantias acerca dos sentidos atribuídos à nossa orientação temporal são gravemente abaladas em nosso presente?
} 
Pensar os processos de subjetivação docente em meio às políticas de avaliação exige assim, sumariar os mecanismos articulatórios mobilizados em relações diferenciais que constituem e fixam, precária e provisoriamente, lugares dentro de uma ordem social específica. Afinal, agir politicamente significa tomar decisões em meio a uma infinidade de possibilidades abertas pela reativação do momento articulatório (crise, deslocamento da estrutura), em termos de identificação com os processos de significação em disputa. É neste processo de identificação que as subjetividades políticas são criadas e formadas. (HOWARTH, 2000). O que significa agir politicamente do lugar da docência? De que maneira os sujeitos posicionados como docentes participam da luta pela significação que envolve a definição, por exemplo, de uma escola democrática?

Esse "tempo de incertezas" no qual vivemos e formulamos nossos problemas de pesquisa nos aponta igualmente para o fato de essa crise não se limitar às instituições e estar também diretamente relacionada aos sujeitos que as inventaram e nelas atuam. Referimo-nos ao que ficou conhecido como a crise do sujeito moderno, produtora de efeitos desestabilizadores dos sentidos hegemônicos de categorias analíticas como sujeito politico e/ou sujeito do conhecimento, tão caros às análises do campo educacional.

Essa perspectiva nos afasta radicalmente das formulações teóricas que explicam a ação política do sujeito seja por um "voluntarismo absoluto", seja pela sua redução ao papel de reprodução das estruturas pré-construídas. Afastando-se de abordagens essencialistas da subjetividade, a abordagem discursiva pós-fundacional oferece ferramentas para que a tensão entre estrutura e agência no campo educacional possam ser explorados por outros caminhos.

Como já mencionado anteriormente, em relação ao termo estrutura, importa sublinhar que as estruturas discursivas são percebidas como sendo "inerentemente contingenciais e maleáveis" (HOWARTH, 2000, p. 121). No caso do termo agência, ele é empregado para traduzir a forma como os atores sociais se inscrevem em processos de identificação, desafiam e/ou transformam as estruturas sociais. Trata-se de problematizar e abandonar a categoria "sujeito" quando essa nos remete a uma noção de subjetividade ("sujeito absoluto") capaz de articular em torno de um centro transcendente - fora pois, do jogo da linguagem- as múltiplas subjetividades.

É nessa perspectiva pois, que apresentamos nosso argumentos e hipóteses sobre a "docência" como um campo de estruturação de uma cultura profissional na qual os sujeitos são simultaneamente posicionados como docentes para cumprir um papel que corresponde a uma estabilidade provisória de sentidos em torno do que se define hegemonicamente como docência 
neste campo e provocados como seres políticos a participarem das lutas pela definição de sua cultura profissional.

Entre as diferentes categorias que configuram a caixa de ferramentas desse quadro teórico, alguns estudiosos das teorizações discursivas têm explorado a categoria demanda, entendo-a como uma potente chave de leitura para a reflexão sobre a luta hegemônica. Entre esses estudiosos Retamozo (2009), cientista politico cujos trabalhos têm como foco os movimentos sociais, vem explorando essa categoria propondo uma metodologia de pesquisa - nomeada por ele de Epistemologia das demandas ${ }^{2}$. De forma sintética, entendo que a potencialidade dessa proposta teórico-metodológica para pensar a interface políticas de avaliação-docência diz respeito ao fato de ela permitir uma leitura do político que leva em consideração tanto a estruturação da ordem social a docência quanto as subjetividades políticas docentes, isto é, tanto os processos de estruturação, quanto os sujeitos que as reproduzem e/ou subvertem.

A categoria demanda é, pois, uma ferramenta importante para compreender os conflitos que emergem na e contra a ordem social, estando diretamente associada ao conceito de subjetividades, ou melhor, como afirma Retamozo (2009, p. 116) "supõe necessariamente a ingerência da subjetividade". O termo demanda pode ser pensado a partir de uma petição/pedido, mas também pode apresentar-se como uma reclamação/reivindicação. Na primeira forma, inicialmente, não está presente uma ideia de conflito, o que não quer dizer que esse pedido não possa vir a transformar-se em reclamação/reivindicação. Nessa última está presente um viés de interpelação imperativa (LACLAU, 2005; RETAMOZO, 2009).

Com efeito, em uma situação onde o momento articulatório é reativado, os processos de subjetivação/identificação desempenham um papel importante na possibilidade de identificar/ significar "uma relação social ou uma situação particular como factível de ser levada ao espaço público" (idem) sob a forma de demanda.

Qualquer ordem social resultante de operações discursivas carrega, portanto, potencialmente, o conflito que pode ser ou não acionado, permitindo que uma posição subalternizada possa assumir o lugar do antagonismo. E é justamente nesse deslocamento das relações de poder assimétricas que emerge como potente a categoria demanda. Afinal para Retamozo ( 2009):

A elaboração da demanda é um aspecto fundamental e logicamente prévio ao antagonismo, ainda que no âmbito aberto do antagonismo ela possa reelabora-se e

\footnotetext{
${ }^{2}$ Embora este autor tenha como foco os movimentos sociais, temos apostado na potencialidade heurística da Epistemologia das Demandas para a compreensão de outros campos de conhecimento e objetos de investigação.
} 
produzir novas demandas. A demanda é produzida no interstício da ordem social como uma "falta" e pode converter-se em veículo de efeitos deslocatórios, algo que dependerá da capacidade de articulação da demanda, mas também do conteúdo (literal ou seu excesso metafórico) (RETAMOZO, 2009, p. 114, tradução nossa).

Cabe ainda destacar que subordinação e antagonismo não são sinônimos. Nem toda posição subalterna constitui necessariamente uma relação antagônica. Para que haja antagonismos é preciso haver fissuras na estrutura que deixa maiores espaços para deslocamentos. É nesse sentido que entendemos que as políticas de avaliação atreladas a políticas de responsabilização com as características que explicitamos parecem buscar limitar deslocamentos docentes em sua relação com o saber. Relação esta vista como de necessário controle pelo poder público de forma a garantir a melhoria da qualidade da educação, reafirmando assim a docência em posição de subalternidade na ordem educacional contemporânea. Retamozo (2009) nos alerta para que "a identificação de relações subalternas nada nos diz ainda da capacidade dessas relações subalternas produzirem atores políticos" (RETAMOZO, 2009, p. 113). Para que uma relação de subalternidade se caracterize como uma relação antagônica é preciso que ela desloque a fronteira hegemônica que sutura provisoriamente as cadeias equivalenciais, produzindo outros antagonismos e hegemonias.

No que diz respeito à docência e considerando a estruturação desigual, hierárquica e excludente do sistema de conhecimento hegemonizado no sistema escolar, é possível afirmar que esta tem ocupado uma posição de subalternidade. Historicamente identificada como um ofício sem saberes, a docência tende a ser vista como um "lugar menor", de menor prestígio quando comparada a outras posições que se relacionam igualmente com o conhecimento legitimado e validado nas escolas públicas, como por exemplo a pesquisa. Como afirma Retamozo (2009), qualquer processo de estruturação :

(...) (que emerge de um ato hegemônico indissociável do poder) produz em seu interior diferenças, exclusões, nomes, lugares, que se naturalizam historicamente, mas que têm o reverso da contingência. Estamos falando da produção-estruturação da desigualdade, da assimetria, das relações de submissão e exploração que surgem como resultado de determinada ordenação social particular na história. A estruturação da sociedade contém assim, uma pluralidade de diferenças (posições de sujeito, no dizer de Laclau e Mouffe, 1985), algumas das quais implica definir lugares dominantes e, portanto, também o seu contrário, subalternos. Nesse sentido, a ordem social contemporânea está atravessada por uma multiplicidade de subordinações (como as de classe, de gênero, as étnicas, ecológicas). (RETAMOZO, 2009, p. 113, tradução nossa). 
Na próxima e última seção continuamos explorando a categoria 'demanda' como ferramenta potente para a compreensão dos processos de subjetivação que contribuem para deslocar o sujeitodocente do lugar da subalternidade em meio a sistemas desiguais e hierarquizados de saberes. Nesse sentido, apresentamos nossa aposta política na produção de demandas antagônicas por parte dos sujeitos posicionados como docentes a partir da sua relação com o principal bem simbólico produzido, distribuído e consumido nas escolas: o conhecimento escolar.

\section{APOSTANDO NA PRODUÇÃO DE DEMANDAS ANTAGÔNICAS}

(...) as demandas emergem como lugar de mediação entre uma situação estrutural de subordinação e a construção de possíveis antagonismos." (RETAMOZO, 2009, p. 113).

Considerando a articulação entre políticas de avaliação e docência na qual investe este texto, importa nesta última seção explorar possibilidades de significação para essa cultura profissional que contribuam para deslocar do lugar da subalternidade, o sujeito docente. Como anteriormente explicitado, essa posição subalterna está diretamente relacionada à imersão dessa profissão, sobretudo o percurso de sua formação, no âmbito de uma cultura universitária configurada e ordenada em torno de um sistema de saberes fortemente hierarquizado. Vimos igualmente que as desigualdades e contradições em uma ordem social não se transformam automaticamente em antagonismos, sendo necessário que os sujeitos que ocupam posições subalternas criem antagonismos a esta mesma ordem considerada injusta, pois somente a criação de antagonismos abre a possibilidade de reconfiguração do ordenamento social.

Os argumentos nos quais vimos apostando em nossos estudos curriculares (AUTOR1, ANO, ANO) consiste em participar das disputas pela significação e estruturação do campo da docência, investindo na potência subversiva da relação do sujeito-docente com o conhecimento escolar. Essa aposta ganha fôlego quando incorporamos à reflexão os debates acerca das políticas de avaliação. Como procuramos destacar anteriormente, nesse campo empírico tanto os discursos produzidos para fortalecer quanto para desestabilizar essas políticas tendem a mobilizar sentidos de 'qualidade' da ação docente envolvendo direta e/ou indiretamente o conhecimento legitimado para ser ensinado e avaliado.

As políticas de responsabilização docente não deixam de ser mecanismos de fixação hegemônica do que é (ou interessa que seja) docência, do que é conhecimento mobilizado desse lugar e de qual tipo de relação entre ambos é privilegiada nesses discursos. Entendemos assim que nesse campo político a luta se desloca da afirmação de uma ideia de autonomia docente abstrata pautada muitas vezes na percepção de um sujeito racional moderno para a compreensão de um 
entendimento de um sujeito em projeto permanente face às possibilidades infinitas de escolhas em um campo de possibilidades cujos limites e fronteiras estão em permanente disputa. Um instrumento de avaliação, seja qual for a escala no qual ele é pensado, é um dispositivo de estabilização de discursos sobre verdades a serem ensinadas. Entrar nessa disputa do lugar da docência significa não apenas lutar pela possibilidade de produzir e aplicar tal instrumento, mas igualmente e sobretudo disputar as lutas pela hegemonização dos discursos sob a forma de conhecimento escolar objetivado que estão sendo avaliados.

Essa argumentação se sustenta, por sua vez, em um sentido particular desse oficio no qual igualmente nos interessa investir e que passa pelo ato de ensinar alguma coisa que valha a pena a alguém. A compreensão dessa singularidade do ofício docente permite produzir sentidos do lugar da docência que valorizem a relação dos professores com o conhecimento escolar não como uma relação mecânica de mera transmissão de um conhecimento produzido em outro lugar, de maior prestígio social, mas como uma relação de poder-saber que reafirme o papel de protagonista do docente no processo de transformação do conhecimento científico/acadêmico em saber escolarizado.

Desse modo, concordamos com a ideia que a reflexão sobre os processos de subjetivação docente pode ser redimensionada quando deslocamos o:

(...) o foco dos sujeitos que ensinam, para os sujeitos que se constituem no processo de ensino e aprendizagem em meio às relações que estabelecem com o conhecimento escolar. Pensar a docência como lócus de produção simultânea de posição de sujeito e de subjetividade política, permite explorar outros sentidos da interface trabalho docente - conhecimento escolar em meio ao acirramento das disputas nas fronteiras antagônicas (GABRIEL, 2015, pp. 438-439, grifos da autora).

Nessa perspectiva abre-se a possibilidade de pensarmos a emergência de subjetividades políticas no campo da estruturação da docência a partir da formulação de demandas de conhecimento capazes de produzir outros antagonismos e outras hegemonias.

Quando uma demanda em forma de petição é atendida prontamente por aqueles que estão em posição de satisfazê-la, finda o problema. Entretanto, é sabido que nas relações sociais há uma grande quantidade de demandas que não são atendidas de forma diferencial, isto é, isoladas, pelos sistemas institucionais. Dessa forma, o acúmulo de demandas insatisfeitas cria entre elas uma relação equivalencial (LACLAU, 2005). A esta pluralidade de demandas Laclau chamará demandas populares a demanda que, satisfeita ou não, permanece isolada, será chamada de demanda democrática. À medida que uma demanda é satisfeita e se isola da cadeia equivalencial que forma 
as demandas populares, ela corre o risco de tornar-se exterior constitutivo destas, pois, como salienta Laclau (2005, p. 108), “as primeiras [demandas democráticas] podem ser incorporadas a uma formação hegemônica em expansão; as segundas [demandas populares] representam um desafio à formação hegemônica como tal.” (tradução nossa).

Essas definições permitem apreender que nem toda demanda é antagônica, sendo, pois, as demandas democráticas, um exemplo disso, uma vez que são reconhecidas e rapidamente incorporadas pelos sistemas institucionais.

A potencialidade de se trabalhar com a categoria demanda está na possibilidade de pensar como sentidos coletivos presentes em cada demanda se convertem em espaços políticos, partindo do pressuposto que é a capacidade de articulação com outras demandas que fortalece as demandas inicialmente produzidas em direção a uma construção antagônica. Caberia então perguntar-nos : Em tempos de acirramento de demandas de diferença, de igualdade e de qualidade que interpelam a escola, qual o lugar atribuído às demandas de conhecimento escolar ? Como a incorporação do debate curricular sobre os processos de produção e de distribuição desse conhecimento pode contribuir para a "identificação de uma situação que tem lugar no interior da ordem social, a qual é considerada como injusta ou indesejável e é apresentada no espaço público como uma demanda insatisfeita" (RETAMOZO, 2009, p. 114, tradução nossa).

\section{A TÍTULO DE FECHAMENTO PROVISÓRIO}

As reflexões aqui trazidas estão longe de esgotar as discussões em torno da complexa relação entre as políticas de avaliação e os processos de subjetivação e objetivação da docência. Fugindo dos perigos dos essencialismos procuramos abordar a questão por meio da tensão entre estrutura e sujeito por uma abordagem discursiva pós-fundacional que considera que toda fixação de sentidos ocorre no campo do político, atravessado pela contingência, o que garante a precariedade de qualquer sentido hegemonicamente fixado. Assim, compreendemos que as políticas de avaliação consistem em estratégias discursivas para fixar a docência em uma posição de subalternidade nos processos educacionais contemporâneos.

A discussão estabelecida ao longo do texto investe no descentramento da estrutura como do sujeito, garantindo assim brechas para a reflexão sobre a agência dos sujeitos posicionados em uma condição de subordinação. Sublinhamos igualmente a importância da formulação de demandas antagônicas que possam deslocar posições subalternizadas. Defendemos igualmente que no caso do campo de estruturação da docência a construção do campo antagônico pressupõe reconhecer o lugar 
incontornável da relação com o conhecimento escolar. O desafio consiste na formulação de demandas de conhecimento que possam ser redimensionadas como populares, isto é suficientemente potentes para desestabilizar formações hegemônicas. Longe de considerarmos que os posicionamentos teórico-políticos tenham alguma pretensão de universalidade, nossa intenção foi esboçar alguns argumentos teóricos que ajudem a provocar outros sentidos de docência em um contexto de ordem social fissurada. Operar com a função discursiva do antagonismo, pela qual é "reativada a lembrança da contingência, do espectro que tudo pode ser diferente" (RETAMOZO, 2009) é um caminho possível para a proposta aqui defendida. Afinal, essa reativação nos parece incontornável quando o que este em jogo é a disputa por sentidos de docência que a legitimem como espaço privilegiado de relação com o saber no processo educacional contemporâneo. 


\section{REFERÊNCIAS}

AFONSO, A. J. Estado, Políticas Educacionais e Obsessão Avaliativa. Contrapontos - Volume 7 - n. 1- p. 11-22 Itajaí, jan./abr. 2007. Disponível em: https://siaiap32.univali.br/seer/index.php/rc/article/view/888/741 Acesso em: 25 jul. 2018.

BROOKE, N. O futuro das políticas de responsabilização educacional no Brasil. Cadernos de Pesquisa, v. 36, n. 128, p. 377-401, mai./ago. 2006. Disponível em: <http://www.scielo.br/pdf/\%0D/cp/v36n128/v36n128a06.pdf>. Acesso em: 25 jul. 2018.

Responsabilização educacional no Brasil. Revista Iberoamericana de Evaluación Educativa, v. 1, n. 1, 2008. Disponível em: <https://revistas.uam.es/index.php/riee/article/view/4684>. Acesso em: 25 jul. 2018.

GABRIEL, C. T. Discurso, demandas e fronteira: articulações teórico-metodológicas na análise de textos curriculares. Revista FAEEBA Educação \& Contemporaneidade, 2013. Disponível em: <http://www.revistas.uneb.br/index. php/faeeba/article/view/750>. Acesso em: 25 jul. 2018.

Docência, demanda e conhecimento escolar: articulações em tempo de crise. Currículo sem Fronteiras, v.

15, n. 2, pp. 425-444, mai./ago, 2015. Disponível em: <http://www.curriculosemfronteiras.org/vol15iss2articles/ gabriel.pdf>. Acesso em: 25 jul. 2018.

HOWARTH, D. Discourse. Buckinghtam: Opens University Press, 2000.

HYPOLITO, Á. M.; IVO, A. A. Políticas Curriculares e Sistemas de Avaliação: Efeitos sobre o Currículo. Revista eCurriculum, São Paulo, n. 11, v. 02, ago, 2013. Disponível em: <http://revistas.pucsp.br/index.php/curriculum/ article/view/16613>. Acesso em: 25 jul. 2018.

LACLAU, E. La razón populista. Buenos Aires: Fondo de Cultura Económica, 2005.

; MOUFFE, C. Hegemonía y estratégia socialista: hacia uma radicalización de la democracia. Bueno Aires: Fonde de Cultura Económica, 2004.

MARCHART, O. El pensamiento político posfundacional: La diferencia política em Nancy, Lefort, Badiou y Laclau. Buenos Aires: Fondo de Cultura Económica, 2009.

MARTINS, M. L. B. Saerjinho: sentidos de avaliação e conhecimento histórico escolar em disputa. $2015.193 \mathrm{f}$. Dissertação (Mestrado em Educação) - Universidade Federal do Rio de Janeiro, Rio de Janeiro, RJ, 2015.

MENDONÇA, D. de. Teorizando o agonismo: crítica a um modelo incompleto. Revista Sociedade e Estado, v. 25 , n. 3, setembro/dezembro, 2010. Disponível em: <http://www.scielo.br/scielo.php?script=sci_arttext\&pid=S0102-6992201 0000300004>. Acesso em: 25 jul. 2018.

PONTUAL, T. C. Remuneração por mérito: desafio para a educação. Fundação Lemann, 2008.

RETAMOZO, M. Las Demandas Sociales y El Estudio de lós Moviminetos Sociales. Santiago: Cinta Moebio, 2009, v. 35, p. 110-127. Disponível em: http://www.facso.uchile.cl/publicaciones/moebio/35/retamozo.pdf Acesso em: 25 jul. 2018.

SILVA, V. G. da. Usos de avaliações em larga escala em âmbito escolar. In: ANPED. Anaius... $36^{\mathrm{a}}$ Reunião Anual. Goiânia, GO> Anped, 2013. Disponível em: 〈http://www.anped.org.br/sites/default/files/gt14_3264_texto.pdf〉. Acesso em: 25 jul. 2018.

et al. Por que secretarias de educação investem em sistemas próprios de avaliação? In: ANPAE. Anais... XXVI Simpósio. Recife PE: Anpae, 2013. Disponível em: <www.anpae.org.br/simposio26/1comunicacoes/Vandre GomesdaSilva-ComunicacaoOral-int.pdf>. Acesso em 25, jul. 2018.

SOUSA, S.Z.; OLIVEIRA, R.P. Sistemas estaduais de avaliação: uso dos resultados, implicações e tendências. Cadernos de Pesquisa, vol. 40, n. 141, p. 793-822, set./dez., 2010. Disponível em: <http://www.scielo.br/scielo.php? pid=S0100-15742010000300007\&script=sci abstract\&tlng=es Acesso em: 25 jul. 2018. 


\section{RESUMO}

O presente texto tem por objetivo analisar processos de subjetivação docente em meio às políticas de avaliação em nossa contemporaneidade a partir das contribuições teóricas dos estudos curriculares mais recentes, em particular aqueles oriundos do estreitamento do diálogo deste campo com as teorizações do discurso na pauta pós-fundacional. Neste exercício teórico, assumindo os efeitos da virada ontológica na produção de uma leitura política do social, significamos a docência como um campo de estruturação profissional que ocupa um lugar subalterno no sistema hierarquizado de saberes e o conjunto de políticas de avaliação como um terreno fértil para sustentar esse argumento. A aposta aqui defendida consiste em afirmar que a valorização dessa cultura profissional implica também na problematização da relação com o conhecimento estabelecida pelo sujeito-docente face às políticas envolvendo diretamente o conhecimento objetivado para ser ensinado na educação básica. A análise sublinha que os processos de subjetivação docente e as possibilidades de subversão ou deslocamento da posição de subalternidade implicam na articulação estabelecida com os processos de objetivação do conhecimento legitimado e avaliado.

Palavras-chave: Políticas de avaliação; currículo; conhecimento escolar; subjetivação docente; virada ontológica.

\section{ASSESSMENT POLICIES AND TEACHER'S SUBJECTIVATION: A POST- FOUNDATIONAL CURRICULAR ANALYSIS}

\section{ABSTRACT}

This present text aims to analyze the teacher's subjectivation processes occurred in the contemporary assessment policies, through the theoretical contributions of the current curricular studies, particularly those originated from the dialogue between such field with the discourse theory in the post-foundational perspective. In our study, we assume the effects of an ontological turn in the production of a social political reading, in order to significate the teaching as a field of professional structuring that occupies a subaltern position in the knowledge hierarchy and the assessment policies as a fertile location to sustain such argument. Our defense consists in affirming that the valuation of this professional culture implies, as well, in the problematization of the relation with the knowledge stablished by subject-teacher, in the face of policies involved directly with the objectivated knowledge to be taught in the basic education. The analyze emphasizes that the teacher's subjectivation processes and the possibilities of subversion or displacement of the subalternity position imply in the articulation stablished with the processes of objectivation of the evaluated and allowed knowledge.

Keywords: Assessment policies; curriculum, school knowledge. Teaching subjectivation; Ontological turn.

\section{POLÍTICAS DE EVALUACIÓN Y SUBJETIVACIÓN DOCENTE: UN ANÁLISIS CURRICULAR POST-FUNDACIONAL}

\section{RESUMEN}

El presente texto tiene como objetivo analizar procesos de subjetivación docente en medio a las políticas de evaluación en nuestra contemporaneidad a partir de las contribuciones teóricas de los estudios curriculares más recientes, en particular aquellos oriundos del estrechamiento del diálogo de este campo con las teorizaciones del discurso en la agenda post-fundacional. En este ejercicio teórico, asumiendo los efectos del cambio ontológico en la producción de una lectura política de lo social, significamos a la docencia como un campo de estructuración profesional que ocupa un lugar subalterno en el sistema jerarquizado de saberes y el conjunto de políticas de evaluación como un terreno fértil para apoyar ese argumento. La apuesta aquí defendida consiste en afirmar que la valorización de esta cultura profesional implica también la problematización de la relación con el conocimiento establecido por el sujeto-docente frente a las políticas que involucran directamente el conocimiento que se pretende enseñar en la educación básica. El análisis subraya que los procesos de subjetivación docente y las posibilidades de subversión o desplazamiento de la posición de subalternidad implican la articulación establecida con los procesos de objetivación del conocimiento legitimado y evaluado.

Palabras clave: Políticas de evaluación; currículo; conocimiento escolar; subjetivación docente; cambio ontológico. 